\title{
The Modes of Dental Caries Prevention with Xylitol
}

\author{
Jihan Turkistani* \\ Pediatric Dentistry, King Abdulaziz Medical City, National Guard Health Affairs, Saudi Arabia
}

*Corresponding author: Jihan Turkistani, Pediatric Dentistry, King Abdulaziz Medical City, National Guard Health Affairs, Jeddah, Saudi Arabia.
Received Date: June 24, 2020

Published Date: June 29, 2020

\section{Introduction}

The importance of dietary factors in the etiology of dental caries has been acknowledged, and the role of proper nutrition in improving the health of the population cannot be disputed [1]. The American Academy of Pediatric Dentistry (AAPD) acknowledges the benefits of sugar substitutes, particularly xylitol as caries preventive strategies on the oral health of infants, children, adolescents, and persons with special health care needs. Thus, the AAPD has intended a policy about the use of xylitol-based products in caries prevention [2].

The discovery of xylitol is credited to two groups of researchers in 1890, the German chemistry professor Fischer, and the French chemist Bertrand [3]. Xylitol is a natural carbohydrate sweetener that belongs to the pentitols (five-carbon sugar alcohol) [4]. The first trials for xylitol were done in the late 1960s and early 1970s in Turku, Finland [5]. A two-year study showed that subjects who had xylitol in their diets as a substitute for sucrose developed almost no new carious lesions compared to the other groups [6]. Based on Turku study results, several other trials and a large number of laboratory studies ensued. The first significant dental recommendations for the use of xylitol began to appear in the United States' dental literature in the early 1990s. Anderson et al. presented the medical model approach to dental caries incorporating sealants, antimicrobials, fluorides, and xylitol [7].

\section{Use of Xylitol in Dental Practice}

The use of xylitol in caries prevention does not require professionals, clinical visits and treatment, equipment, or repeated indi vidual check-ups. Therefore, one can easily start a preventive pro gram with xylitol, while professionals can use their clinical hours to treat subjects with more acute needs [8]. The use of xylitol in dietary foods has been approved by the United States (U.S.) Food and Drug Administration since 1963. It has been introduced for children in different forms, such as candies, gum, syrups, gelatin, in addition to other products like multivitamins, toothpaste, and oral rinses [9]. Chewing gum has been established as the most effective vehicle for the delivery of xylitol to the oral cavity. However, though this may be an effective means of consuming xylitol for most adult populations, it is a limiting factor for its use in small children and as a public health method of intervention in organized preschool programs [10]. Additionally, dentists should emphasize that xylitol chewing gum is an added measure, not a replacement for other preventive programs like fluoride, consciously applied oral hygiene practices and regular dental visits $[11,12]$.

Xylitol-sweetened gum is not as available in the U.S. as are sucrose- and sorbitol-sweetened gums. Evidence showed that xylitol-sweetened gum offers more caries reduction benefits than did sorbitol-sweetened gum. Still, chewing sorbitol-sweetened gum several times per day is better than chewing sugared gum in reducing caries $[11,13,14]$. Sorbitol is another sugar alcohol that is frequently used in several sugar-free chewing gums and over-thecounter medicines $[13,15]$. Due to the relatively high cost of xylitol, sorbitol and xylitol are often combined with a better clinical effect than with pure sorbitol $[16,17]$. Sorbitol should be considered a low cariogenic sweetener rather than a non-cariogenic one because the 
consumption of larger amounts increases both the acid production in plaque and the number of sorbitol-fermenting micro-organisms [18].

The long-term effects of xylitol chewing gum have been demonstrated in several studies [19-21]. Teeth erupting after the end of the gum-chewing program showed the most significant long-term caries reductions. For the utmost outcome, chewing xylitol gum should be started at least one year before permanent teeth erupt, i.e., during preschool and early elementary school years [22]. Moreover, several clinical studies provide evidence of the effectiveness of xylitol-sweetened gum in reducing maternal transmission of cariogenic bacteria [23-27]. A range of 6 to 10 grams divided into three times per day is necessary for xylitol chewing gum to be useful $[19,20,28-30]$. The main side effect associated with xylitol consumption is osmotic diarrhea. It usually occurs when consumed in large quantities, four to five times those needed for the prevention of dental caries [31].

\section{Mechanism of Caries Inhibition}

Most oral micro-organisms do not ferment xylitol, and its caries-reducing effects have been attributed mainly to this lack of fermentation. However, specific effects on microbial growth and metabolism, on certain salivary factors, and the physicochemical processes of de- and remineralization have also been claimed [3234].

\section{Effect on bacteria}

Dental plaque formation: Several studies have shown xylitol to reduce the amount of dental plaque formation, adhesiveness, and acidogenic potential of dental plaque when compared with the chewing of sucrose-containing gums or not chewing gum [14,3537].

Bacterial metabolism \& growth inhibition: Sugar transport into bacterial cells plays a role in the expression of the virulence (cariogenicity) of Streptococcus mutans. The high-affinity phosphoenolpyruvate-dependent sugar: phosphotransferase system (PTS) is the principal route for transporting most sugars in oral streptococci. The other two transport systems are: fructose-specific and sucrose phosphorylase [38]. Some carbohydrate sweeteners are neither taken up nor metabolized to acids by Streptococcus mutans. Since xylitol possesses a 5-carbon sugar alcohol structure, it is taken up via PTS by Streptococcus mutans. Still, it cannot be metabolized to acid and is accumulated as non-metabolizable, toxic xylitol phosphate [most likely xylitol 5-phosphate], resulting in inhibition of both bacterial growth and acid production. Xylitol phosphate is further dephosphorylated to xylitol with the waste of phosphoenolpyruvate potential. This futile cycle can also retard the growth of Streptococcus mutans [34,39,40]. Furthermore, xylitol phosphate inhibits several enzymes of the glycolytic pathway (e.g., phosphoglucoisomerase, 6-phosphofructokinase, and pyruvate kinase) [40].

Most of the mutans streptococci strains tested (e.g., S. mutans, S. rattus, and S. sobrinus strains) are sensitive to xylitol when grown in the presence of glucose plus xylitol $[38,41-46]$. Sensitivity to xylitol was defined as an inhibition of the growth of wild-type strains in the presence of xylitol and is thus called "xylitol-sensitive" (X.S.) strains [41]. On the other hand, an earlier in vitro study in 1972 showed that when Streptococcus cells were transferred from normal media into xylitol media and the overall bacterial cell metabolism seemed to be retarded. Consequently, the induction of aminopeptidase-like enzymes occurred. It may suggest that the cells were forced to use proteins and peptides to a greater extent for synthetic purposes. After several months of storage in polyol-containing broth, the cells grew almost normally, and the induction of aminopeptidases by xylitol was reduced almost to the level exerted by cells grown in a normal medium. This suggests that xylitol, in long-term use, could be used by oral micro-organisms [47]. Therefore, it is necessary to further investigate mechanisms of effects of xylitol on Streptococcus mutans metabolism, especially at the molecular level [48]. Moreover, other in vitro study showed that xylitol is not phosphorylated by the fructose PTS in the presence of fructose.43 Since fructose competes with xylitol for the fructose PTS and prevents phosphorylation of xylitol by Streptococcus mutans strains. Therefore, no significant growth inhibition is observed when mutans strains are cultured on fructose or sucrose in the presence of xylitol $[41,46]$. Such competition between xylitol and fructose for the fructose PTS, could result in selective pressure of variable efficiency. This selective pressure indicates that fructose and sucrose may not prevent the uptake and the phosphorylation of xylitol by growing cells, as was thought previously, and enough growth inhibition could occur. Evidence for a selective pressure by xylitol includes:

1) A variation in the inhibition of the growth of a given strain, depending on the nature of the growth sugar, whether a PTS sugar (glucose, fructose, or sucrose) or a non-PTS sugar (lactose).

2) The emergence, or lack of emergence, of xylitol-resistant populations during growth on any given sugar depending on the mutans species or strains.

3) A variation in the time it takes for xylitol-resistant populations to emerge [46].

Some in vitro studies have studied the inhibitory effect of xylitol on acid production at several $\mathrm{pH}$ levels under the strictly anaerobic condition found in the deep layer of dental plaque. At pH 5.5-7.0, xylitol inhibited the rate of acid production from glucose. Also, the activity of phosphoenolpyruvate PTS for xylitol was greater at higher $\mathrm{pH}$ resulting in the accumulation of intracellular xylitol phosphate. Though these results were not evident at pH 5.0, and it is suggested that xylitol could be incorporated more efficiently at higher or neutral $\mathrm{pH}[40,49]$. Besides, certain strains of salivary lactobacilli, which are involved in the progression of carious lesions, can metabolize polyols resulting in $\mathrm{pH}$ drop to values sufficiently low to demineralize the hard tissues of the teeth. Therefore, the limited information available concerning fermentation rate of these polyols and the formation of various metabolic end products by lactobacilli fermenting these polyols necessitates further studies [50]. 
The emergence of xylitol-resistant mutants: Long-term consumption of xylitol leads to the emergence of xylitol-resistant mutans populations in humans $[41,44,46,51,52]$. These "xylitol-resistant" (X.R.) mutants are unable to accumulate the toxic xylitol phosphate due to lack of fructose PTS activity responsible for xylitol uptake and phosphorylation [41,43-45]. Two operons encoded the fructose PTS activity. The fru I gene encodes for a protein that transports fructose and xylitol. Its deletion renders the mutant cell's metabolism and growth resistant to xylitol. By contrast, fru CD gene encodes for a protein that transports fructose but does not transport xylitol. Fru CD deletion does not render the mutant cell's metabolism and growth resistant to xylitol. In xylitol-resistant strains, the fru I gene was deleted.38 A shift from xylitol-sensitive to xylitol-resistant mutans streptococci populations in the plaque of xylitol consumers does not necessarily indicate a loss of the anti-cariogenic properties of xylitol. Various preliminary results supported the hypothesis that xylitol-resistant mutants are less virulent and less cariogenic than their wild-type parent strains. A study by Tanzer et al. showed that X.R. strains of Streptococcus mutans are of diminished virulence by compromised colonization of the teeth and compromised ability to induce lesions that penetrate dentin [53]. Such characteristics might be beneficial and maybe one of the numerous modes of action of this caries-preventive carbohydrate sweetener. Xylitol-resistant mutants are also persisting many years after the xylitol is removed from the diet [51].

Expression of HSP: Some environmental conditions make living organisms express different adaptive responses that allow survival under the physiological stress created by a new environment. The emergence of mutans populations is not the only way to survive in the new environment. Thermal shock studies led to the discovery of heat shock proteins (HSP), also called stress proteins.54 Stress proteins are generally divided into families: HSP-60 and HSP-70. They are needed for essential cellular functions and adaptation to the environment [55-58]. A study investigating the effect of a xylitol exposure on the expression of HSP-60 and HSP70 proteins in Streptococcus mutans was carried out. The results suggest that xylitol creates a stressful environment that disturbs protein synthesis and reduces the expression of HSP-70 and HSP60 proteins in the xylitol-sensitive Streptococcus mutans but not in the xylitol-resistant natural mutant strain [59]. Since the stressing action of a chemical agent is mediated through its incorporation into the cell; then it could be easy to explain the lack of xylitol effect on xylitol-resistant cells by the absence of xylitol uptake by these natural mutants [60].

Glucan-binding protein $\mathbf{C}$ induction: Another adaptive response that allows survival under the physiological stress created by a new environment due to the accumulation of non-metabolizable xylitol phosphates was described by the experiments of Sato et al. $[48,61]$ It was noticed that xylitol has other target sites, i.e., induction of a glucan-binding protein $\mathrm{C}(\mathrm{GbpC})$ gene expression. The GbpC protein mediates dextran-dependent aggregation (ddag), which mediates adhesion on surfaces such as dental plaque under normal circumstances. Therefore, for Streptococcus mutans, elevated $\mathrm{GbpC}$ expression may be disadvantageous to tooth adhesion (i.e., less ability to adhere) depending on how saliva is moving in the oral environment. The results of Sato et al. studies could explain earlier findings by Trahan et al., who observed that the proportion of xylitol-resistant mutans streptococci did not increase in dental plaque but did so in saliva as a result of more easily shedding of xylitol-resistant strains from the tooth surface than xylitol-sensitive strains [51]. Moreover, this explanation is often used to explain reduced plaque formation and reduced colonization of mutans streptococci after frequent use of xylitol [62].

\section{Effect on demineralization and remineralization process}

Data analysis from clinical and laboratory studies support the hypothesis that xylitol promotes remineralization and can arrest established dental caries in children [63-65]. Another study showed that histologic and physiochemical changes in dentin caries lesions, which are typical of arrested (rehardened) lesions were more seen in subjects with regular long-term use of xylitol chewing gum than other subjects. The hard, although thin surface layer could be attributable to the precipitation of calcium phosphate salts in the lesion's outer zone, enclosing the advancing caries process. The propagation of the process requires that the micro-organisms that have invaded the tissue continue to receive nutrients. The availability of nutrients is impaired by the formation of a hard barrier and by the washing action of saliva [66]. This suggests that xylitol, in addition to its non-cariogenic effect, may have therapeutic effects. More studies are needed to support the caries inhibitory benefits of xylitol.

\section{Effect on saliva}

Peroxidase activity: Lactoperoxidase belongs to the natural defense mechanisms of the oral cavity; it is attributed to the possible inhibition of lactobacillus and Streptococcus growth. It was found that the overall salivary peroxidase activity was increased fourfold to tenfold in persons receiving a strict xylitol diet for two years. It is suggested that the xylitol-induced elevation of the salivary lactoperoxidase activity and the anticarcinogenic properties of xylitol are partly interrelated phenomena [67].

Salivary flow stimulation: Undoubtedly, increased saliva secretion results in a higher salivary $\mathrm{pH}$, buffer capacity, and glucose clearance. Since saliva stimulation is typical for all chewing gums, it was practically impossible to measure the role of salivary stimulation by xylitol chewing gum in all studies in this field [68]. Aguirro-Zero et al. studied the effect of chewing xylitol gum on the salivary flow rate by comparing four groups: no gum, sucrose, sorbitol, and xylitol gum. The findings did not show any significant effect on the salivary flow [69].

Clearance of oral cavity: Chewing of any gum could have a mechanical cleaning effect, but do not affect Streptococcus mutans 
counts. In a study by Soderling et al., there was no effect on either the amount of plaque or the numbers of Streptococcus mutans in plaque and saliva in the placebo base group. They concluded that polyols are active ingredients of chewing gums that can modulate the amount of plaque and its microbial composition [35]. However, the importance of chewing would also explain why gum pellets with a harder texture were more effective in caries prevention than were softer gum sticks, as demonstrated in the Belize study $[28,70]$. Moreover, the frequency of chewing may be more important than the actual daily dose of xylitol. In the study by Isokangas, the chewing of xylitol gums containing $3.5 \mathrm{~g}$ xylitol three times daily (total daily dose, $10.5 \mathrm{~g}$ ) reduced caries incidence significantly, whereas 7 to $9 \mathrm{~g}$ of xylitol, chewed fewer than three times, gave no significant reduction in caries increment [71].

\section{Conclusion}

Xylitol is a natural sugar substitute with anti-cariogenic properties. Data from earlier studies indicate that xylitol can reduce the occurrence of dental caries in schoolchildren and young children via their mothers. Several mechanisms have demonstrated the anti-cariogenic effect of xylitol: reducing mutans streptococci counts, inhibiting plaque accumulation and enamel demineralization, and enhancing remineralization of early lesions. The effective daily dose of xylitol is 6 to $10 \mathrm{~g}$, divided into 3 to 5 times chewed for a minimum of five minutes after meals. There is a demand for providing less expensive xylitol-containing products that should make it more accessible to public health programs directed to high-risk preschool populations.

\section{Acknowledgement}

I want to express my special thanks and sincere gratitude to my supervisors during the Master's postgraduate program, Dr. Najlaa Alamoudi and Dr. Azza Hanno for giving me this golden opportunity and for their continued support and assistance.

\section{Conflict of Interest}

No conflict of interest.

\section{References}

1. Gussy MG, Waters EG, Walsh O, Kilpatrick NM (2006) Early childhood caries: Current evidence for etiology and prevention. J Paediatr Child Health 42: 37-43.

2. (2016) American Academy on Pediatric Dentistry Council on Clinical Affairs. Policy on the Use of Xylitol. Pediatr Dent 38(6): 47-49.

3. Makinen KK (2000) The rocky road of xylitol to its clinical application. J Dent Res 2000 79(6): 1352-1355.

4. Lindley MG, Birch GG, Khan R (1976) Sweetness of sucrose and xylitol. Structural considerations. J Sci Fd Agric 27(2): 140-145.

5. Scheinin A, Mäkinen KK, Ylitalo K (1976) Turku sugar studies, V: final report on the effect of sucrose, fructose and xylitol diets on the caries incidence in man. Acta Odont Scand 34(4): 179-216.

6. Scheinin A, Mäkinen KK, Ylitalo K (1974) Turku sugar studies I. An intermediate report on the effect of sucrose, fructose and xylitol diets on the caries incidence in man. Acta Odontologica Scandinavica. 32(6): 383-412.
7. Anderson MH, Bales DJ, Omnell KA (1993) Modern management of dental caries: the cutting edge is not the dental bur. J Am Dent Assoc 124(6): 36-44.

8. Alanen P, Holsti ML, Pienihakkinen K (2000) Sealants and xylitol chewing gum are equal in caries prevention. Acta Odontol Scand 58: 279-284.

9. Jorge L Castillo, Peter Milgrom, Susan E Coldwell, Ramon Castillo, Rocio Lazo (2005) Children's acceptance of milk with xylitol or sorbitol for dental caries prevention. BMC Oral Health 5: 1-6.

10. Milgrom P, Rothen M, Milgrom L (2006) Developing public health interventions with xylitol for the U.S. and US-associated territories and states. Suom Hammaslaakarilehti 13(10-11): 2-11.

11. Burt BA (2006) The use of sorbitol and xylitol-sweetened chewing gum in caries control. J Am Dent Assoc 137: 190-196.

12. Autio JT, Courts FJ (2001) Acceptance of the xylitol chewing gum regiment by preschool children and teachers in a Head Start program: a pilot study. Pediatr Dent 23(1): 71-74.

13. Birkhed D, Edwardsson S, Kalfas S, Svensäter G (1984) Cariogenicity of sorbitol. Swed Dent J 8(3): 147-154.

14. Holgerson PL, Sjöström I, Stecksén-Blicks C, Twetman S (2007) Dental plaque formation and salivary mutans streptococci in schoolchildren after use of xylitol-containing chewing gum. Int J Paediatr Dent 17(2): 79-85.

15. Birkhed D, Bar A (1991) Sorbitol and dental caries. In: Impacts on nutrition and health. Simopoulos AP (edt.) 65: Basel, Karger, pp: 1-37.

16. Birkhed D, Edwardsson S, Wikesjo U, Ahlden ML, Ainamo J (1983) Effect of 4 days consumption of chewing gum containing sorbitol or a mixture of sorbitol and xylitol on dental plaque and saliva. Caries Res 17: 76-88.

17. Soderling E, Makinen KK, Chen CY, Pape HR, Loesche W, et al. (1989) Effect of sorbitol, xylitol and xylitol/sorbitol chewing gums on dental plaque. Caries Res 23: 378-384.

18. Birkhed D, Svensäter G, Edwardsson S (1990) Cariological studies of individuals with long-term sorbitol consumption. Caries Res 24: 220223.

19. Alanen P, Isokangas P, Gutmann K (2000) Xylitol candies in caries prevention: results of a field study in Estonian children. Community Dent Oral Epidemiol 28: 218-224.

20. Hujoel PP, Makinen KK, Bennett CA, Isotupa KP, Isokangas PJ, et al. (1999) The optimum time to initiate habitual xylitol gum-chewing for obtaining long term caries prevention. J Dent Res 78:797-803.

21. Isogangas P, Mäkinen KK, Tiekso J, Alanen P (1993) Long-term effect of xylitol chewing gum in the prevention of dental caries: a follow-up 5 years after termination of a prevention program. Caries Res 27(6): 495498

22. Autio JT (2002) Effect of xylitol chewing gum on salivary streptococcus mutans in preschool children. ASDC J Dent Child 81-86.

23. Isokangas P, Söderling E, Pienihakkinen K, Alanen P (2000) Occurrence of dental decay in children after maternal consumption of xylitol chewing gum, a follow-up from 0 to 5 years of age. J Dent Res 79: 1885-1889.

24. Söderling E, Isokangas P, Pienihakkinen K, Tenovuo J (2000) Influence of maternal xylitol consumption on acquisition of mutans streptococci by infants. J Dent Res 79: 882-887.

25. Söderling E, Isokangas P, Pienihakkinen K, Tenovuo J, Alanen P (2001) Influence of maternal xylitol consumption on mother-child transmission of mutans streptococci: 6-year follow-up. Caries Res 35(3): 173-177.

26. Thorild I, Lindau B, Twetman S (2003) Effect of maternal use of chewing gums containing xylitol, chlorhexidine or fluoride on mutans streptococci colonization in the mothers' infant children. Oral Health Prev Dent 1(1): 53-57.

27. Thorild I, Lindau B, Twetman S (2004) Salivary mutans streptococci and dental caries in three-year-old children after maternal exposure to 
chewing gums containing combinations of xylitol, sorbitol, chlorhexidine, and fluoride. Acta Odontol Scand 62: 245-250.

28. Makinen KK, Benett CA, Hujoel PP, Isokangas PJ, Isotupa KP, et al. (1995) xylitol chewing gums and caries rates: a 40-months cohort study. J Dent Res 74: 1904-1913.

29. Isokangas P. Alanen P, Tiekso J, Makinen KK (1988) Xylitol chewing gum in caries prevention: a field study in children. J Am Dent Assoc 117: 31520.

30. Isokangas P, Tiekso J, Alanen P, Makinen KK (1989) Long-term effect of xylitol chewing gum on dental caries. Community Dent Oral Epidemiol 17: 200-203.

31. Lynch H, Milogrom P (2003) Xylitol and Dental Caries: An Overview for Clinicians. J Calif Dent Assoc 31(3): 205-209.

32. Makinen KK, P L Mäkinen, H R Pape, J Peldyak, P Hujoel, et al. (1996) Conclusion and review of the "Michigan Xylitol Programme" (19861995) for the prevention of dental caries. Int Dent J 46: 22-34.

33. Knuuttila ML, Makinen K (1975) Effect of xylitol on the growth and metabolism of Streptococcus mutans. Caries Res 9: 177-189.

34. Trahan L (1995) Xylitol: a review of its action on mutans streptococci and dental plaque-its clinical significance. Int Dent J 45: 77-92.

35. Soderling E, Trahan L, Tammiala-Salonen T, L Häkkinen (1997) Effects of xylitol, xylitol-sorbitol, and placebo chewing gums on the plaque of habitual xylitol consumers. Eu Oral Sci 105: 170-177.

36. Makinen KK, Saag M, Isotupa KP, Olak J, Nommela R, et al. (2005) Similarity of the effect of erythritol and xylitol on some risk factors of dental caries. Caries Res 39: 207-215.

37. Sengun A, Sari Z, Ramoglu SI, Malkoc S, Duran I (2004) Evaluation of the Dental Plaque pH Recovery Effect of a Xylitol Lozenge on Patients with Fixed Orthodontic Appliances. Angle Orthod 74: 240-244.

38. Wen ZT, Browngardt C, Burne RA (2001) Characterization of two operons that encode components of fructose-specific enzyme II of the sugar: phosphotransferase system of Streptococcus mutans. FEMS Microbiol Lett (205): 337-42.

39. Assev A, Stig S, Scheie AA (2002) Cariogenic traits in xylitol-resistan and xylitol-sensitive mutans streptococci. Oral Microbiol Immunol 17 95-99.

40. Miyasawa-Hori H, Aizawa S, Takahashi N (2006) Difference in the xylitol sensitivity of acid production among Streptococcus mutans strains and the biochemical mechanism. Oral Microbiol Immunol 21(4): 201-205.

41. Trahan L, Mouton C (1987) Selection for Streptococcus mutans with an altered xylitol transport capacity in chronic xylitol consumers. J Dent Res 66: 982-988.

42. Vadeboncoeur C, Trahan L, Mouton C, Mayrand D (1983) Effect of xylito on the growth and glycolysis of acidogenic oral bacteria. J Dent Res 62: 882-884.

43. Trahan L, Bareil M, Gauthier L, Vadeboncoeur C (1985) Transport and phosphorylation of xylitol by a fructose phosphotransferase system in Streptococcus mutans. Caries Res 19: 53-63.

44. Drean MF, Trahan L (990) A new method for the detection and enumeration of xylitol-resistant (fructose-PTS-) strains of Streptococcus mutans from pure cultures and human saliva. Microbial Ecol Hlth Dis 3: 113-120

45. Trahan L, Neron S, Bareil M (1991) Intracellular xylitolphosphate hydrolysis and efflux of xylitol in Streptococcus sobrinus. Oral Microbiol Immunol 6: 41-50.

46. Trahan L, Bourgeau G, Breton R (1996) Emergence of multiple xylitolresistant (frucyose PTS) mutants from human isolates of Mutans Streptococci during growth on dietary sugars in the presence of xylitol. J Dent Res 11: 1892-1900.
47. Makinen k (1972) Enzyme dynamics of cariogenic streptococcus: The effect of xylitol and sorbitol. J Dent Res 51(2): 403-408.

48. Sato Y, Yamamoto Y, Kizaki H (2000) Xylitol-induced elevated expression of the gbpC gene in a population of Streptococcus mutans cells. Eur J Oral Sci 108: 538-545.

49. Miyasawa H, Iwami Y, Mayanagi H, Takahashi N (2003) Xylitol inhibition of anaerobic acid production by Streptococcus mutans at various $\mathrm{pH}$ levels. Oral Microbiol Immunol 18: 215-219.

50. Badet MC, Richard B, Dorignac G (2001) An in vitro study of the pHlowering potential of salivary lactobacilli associated with dental caries. J Appl Microbiol 90: 1015-1018.

51. Trahan L, Sbderling E, Drean MF, Chevrier MC, Isokangas P (1992) Effect of xylitol consumption on the plaque-saliva distribution of mutans streptococci and the occurrence and long-term survival of xylitolresistant strains. J Dent Res 71: 1785-1791.

52. Stecksen-Blicks C, Lif Holgerson P, Olsson M, Bylund B, Sjostrom I, et al. (2004) Effect of xylitol on mutans streptococci and lactic acid formation in saliva and plaque from adolescents and young adults with fixed orthodontic appliances. Eur J Oral Sci 112: 244-248.

53. Tanzer JM, Thompson A, Wen ZT, Burne RA (2006) Streptococcus mutans: Fructose transport, Xylitol resistance, and Virulence. J Dent Res 85(4): 369-73.

54. Van Eden W, Young DB (1996) Stress proteins in medicine. Marcel Dekker, New York, USA.

55. Ang D, Liberek K, Skowyra D, Zylicz M, Georgopoulos C (1991) Biological role and regulation of the universally conserved heat shock proteins. J Biol Chem 266: 2433-2436.

56. Bukau B, Walker GC (1990) Mutation altering heat shock specific subunit of RNA polymerase suppresses major cellular defects of Escherichia coli mutants lacking the DnaK chaperone. EMBO J 9: 4027-4036.

57. Foster JW (1991) Salmonella acid shock proteins are required for the adaptive acid tolerance response. J Bacteriol 173: 6896-6902.

58. Spence J, A Cegielska, Georgopoulos C (1990) Role of Escherichia coli heat shock proteins DnaK and HtpG (C62.5) in response to nutritional deprivation. J Bacteriol 172: 7157-7166.

59. Hrimech M, Mayrand D, Grenier D, Trahan L (2000) Xylitol disturbs protein synthesis, including the expression of HSP-70 and HSP-60, in Streptococcus mutans. Oral Microbiol Immunol 15: 249-257.

60. Trahan L, Bareil M, Gauthier L, Vadeboncoeur C (1985) Transport and phosphorylation of xylitol by a fructose phosphotransferase system in Streptococcus mutans. Caries Res 19: 53-63.

61. Sato Y, Yamamoto Y, Kizaki H (1997) Cloning and sequence analysis of the gbpC gene encoding a novel glucan-binding protein of Streptococcus mutans. Infect Immun 65: 668-675.

62. Van Loveren C (2004) Sugar alcohols: what is the evidence for cariespreventive and caries therapeutic effects? Caries Res 38: 286-293.

63. Kandelman D, Gagnon G (1990) A 24-month clinical study of the incidence and progression of dental caries in relation to consumption of chewing gum containing xylitol in school preventive programs. J Dent Res 69: 1771-1775.

64. Rekola M (1989) Correlation between caries incidence and frequency of chewing gum sweetened with sucrose or xylitol. Proc Finn Dent Soc 85(1): 21-24

65. Smits MT, Arends J (1988) Influence of extraoral xylitol and sucrose dippings on enamel demineralization in vivo. Caries Res 22(3): 160-165.

66. Makinen KK, Chiego DJ, Allen P, Bennett C, Isotupa KP, et al. (1998) Physical, chemical, and histologic changes in dentin caries lesions of primary teeth induced by regular use of polyol chewing gums. Acta Odontol Scand 56: 148-156. 
67. Makinen KK, Tenovuo J, Scheinin A (1976) Xylitol-Induced increase of lactoperoxidase activity. J Dent Res 55: 652-660.

68. Alanen P (2001) Does chewing explain the caries-preventive results with xylitol. J Dent Res 80(7): 1600-1601.

69. Aguirre-Zero, Zero DT, Proskin HM (1993) Effect of chewing xylitol chewing gum on salivary flow rate and the acidogenic potential of dental plaque. Caries Res 27: 55-59.
70. Makinen KK, Hujoel PP, Bennett CA, Isotupa KP, Makinen PL, et al. (1996) Polyol chewing gums and caries rates in primary dentition: a 24-month cohort study. Caries Res 30: 408-4017.

71. Isokangas P (1987) Xylitol chewing gum in caries prevention. A longitudinal study on Finnish school children. Proc Finn Dent Soc 83(Suppl I): 1-117. 